\title{
Depression and the associated factors among traumatized patients admitted at University of Gondar and Felege-Hiwot comprehensive specialized hospital, Northwest, Ethiopia
}

\section{Asnakew Worku}

Gondar University Hospital

Getachew Tesfaw Desalegn ( $\sim$ getachewtesfaw@gmail.com )

University of Gondar College of Medicine and Health Sciences https://orcid.org/0000-0003-4547-9732 Berhanie Getnet

University of Rwanda College of Medicine and Health Sciences

\section{Research}

Keywords: Depression, Physical Trauma Patients, Ethiopia

Posted Date: May 25th, 2021

DOI: https://doi.org/10.21203/rs.3.rs-550098/v1

License: (c) (1) This work is licensed under a Creative Commons Attribution 4.0 International License. Read Full License 


\section{Abstract \\ Background}

Depression is the main factor of impairment in many areas of function that affects almost all age groups and which also influences on mental and physical health. However, it negatively impacts quality of life and social activities, research into depression and the associated factors among people with traumatized patients in low-and middle-income countries are limited. Therefore, the present study was aimed at identifying the magnitude and associated factors of depression among traumatized patients have a pivotal role for further intervention these vulnerable people.

\section{Methods}

An institutional-based cross-sectional study was conducted at Felege-Hiwot and the University of Gondar comprehensive specialized hospital from March 11/2020 to April 12/2020, by using a structured and semi-structured questionnaire. A systematic random sampling was used to recruit a total of 422 patients. The standard patient health questionnaire (PHQ-9) was used to identify the prevalence of depression by employing a face to face interview. Bivariate and multivariate logistic regression analysis was used to identify associated factors with depression. Statistical significance was declared on $95 \%$ of confidence interval at $P \otimes 0.05$.

\section{Results}

The prevalence of depression was found to be $37.2 \%$ with $95 \%$ (Cl: $32.7-41.5 \%)$. In the multivariate logistic regression; being single $(\mathrm{AOR}=2.36,95 \%, \mathrm{Cl}: 1.31,4.21)$, history of chronic medical illness $(\mathrm{AOR}=$ $3.79,95 \%, \mathrm{Cl}: 1.19,12.08)$, anxiety symptoms (AOR $=3.81,95 \%, \mathrm{Cl}: 2.11,6.85)$, poor and moderate social supports ( $\mathrm{AOR}=4.59,95 \%, \mathrm{Cl}: 2.36,8.91)$ and $(\mathrm{AOR}=4.34,95 \%, \mathrm{Cl}: 2.23,8.45)$, respectively, and moderate perceived threat to life $(A O R=2.66,95 \%, \mathrm{Cl}: 1.58,4.47)$ were factors significantly associated with depression.

\section{Conclusion}

In this study revealed that depression among physical trauma patients was considerable too high. Being single, chronic medical illness, anxiety, poor and moderate social support, and moderate perceived stress were factors significantly associated with depression. The ministry of health and other concerned health organizations may find the current finding useful for early detection, prevention, and intervention strategies to minimize the factor of depression in trauma survivors.

\section{Introduction}


Trauma has negative impacts which include morbidity and mortality of patients with differences in ages and injury severity (1). It is also a psychological shock to individuals who are exposed to an event that involves actual and unexpected death or serious injuries immediately after individuals have experienced an event (2). Among common forms of tragedies which involve both natural and manmade catastrophic events, several people are exposed to awful life-threatening circumstances such as conflicts (wars), fire and car and other vehicle accidents, rape and the like (2). It has been noted that the rates of exposure to a traumatic event can vary depending on the age of the person, country of origin and occupation (3). Physical trauma involves hurt to the individual body, which may be resulted from accidents, falls, suicidal attempts, interpersonal violence, burns, poisoning, and work associated accidents(4)

More than 1.5 million people die and distressed from severe trauma-related illnesses every year, and essentially more people experience impacts of non-deadly harm realized by violence (5). Around three million individuals are discharged in America from hospitals every twelve months after physical injury (6). Around 51.4 million non-lethal violence-related to wounds are dealt with every year in medical emergencies clinic in the United States (7). In Western Europe, 670,000 violence-related injuries require treatment each year (8). According to the 2000-2020 World Health Organization (WHO) estimated, road traffic-correlated death will be to increase with $80 \%$ in low-and middle-income nations (9). The evidence showed that Sub-Saharan Africa in 2015, the accident was accounted for 32\% (10). The evidence from East Africa like Sudan, 2014, and Tanzania, 2005 showed that there is a significant developing burden of traumatic events $(11,12)$. Being one of the developing nations, an accident is a typical general health problem in Ethiopia (13). The finding from Gondar referral hospital showed that the traumatic events accounted for $25 \%$ of surgical problems in 2015 (14). The trauma has negative impacts which include morbidity and mortality of patients with differences in ages and injury severity(15).

Depression presents with depressed mood, loss of interest or pleasure, decreased energy, feelings of guilt or low self-worth, disturbed sleep or appetite, and poor concentration; depression is a significant contributor to the global burden of disease and affects people in all communities across the world. Today, depression is estimated to affect 350 million people (16). In Ethiopia, depression contributes to about $6.5 \%$ of the burden of diseases (17). Depression is a common situation next traumatic physical injury requiring hospitalization and is related with major damage in functional status $(18,19)$. In addition to the challenges posed to physical health, persons who expose physical injuries are at risk for major depression (20). Depression later on physical trauma is related with poor health outcomes including impaired physical functioning and disability and lower quality of life (21). A longitudinal investigation of terrible accidents showed that depression is frequently occurred after experiencing traumatic events (22).

One study done in Australia showed that an unexpected traumatic situation could not only contribute physical injury but also it might lead to survivors an increased risk for depression (23). Some literatures indicate that depression, and anxiety are the most widely recognized as mental problems after encountering trauma incidence (tragedies), which shatters the psychological well-being of an individual that is impacting his/her physical, psychological, social, and occupational functioning shortly after the accident $(24,25)$. 
One review study reported that people who were exposed to an injury, people with earlier PTSD as well as other form of mental problems are at risk for developing depression when faced with another unpleasant stress (26). Another study reported that motor vehicle accident survivors, history of mental treatment, and earlier traumatic events could be the risk factors depression (27).

Many epidemiological studies have shown that depressive disorder is widespread in patients with exposed physical trauma, and deteriorate the health status of the victim by increasing morbidity and eventually leading to mortality. However, these circumstances have not been noticed, and this has been evidenced by the lack of studies targeting prevalence of depression and associated factors among exposed physical trauma in these study area, and in Ethiopia at large. In other words the prevalence of depression in patients with exposed physical trauma admitted at the University of Gondar and FelegeHiwot comprehensive specialized hospital is not known. Considering this gap the study will play a significant role in filling the gap by revealing the unknown.

\section{Materials And Methods}

Study design

An institution based cross-sectional study design was conducted among traumatized patients who were exposed for multiple forms of physical trauma and admitted inpatient care unit in different wards from March 2020 to April 2020. The research was conducted at Felege-Hiwot and University of Gondar Comprehensive Specialized referral hospital situated at Bahir Dar and Gondar respectively.

\section{Study area}

The research was conducted at Felege-Hiwot and Gondar University Comprehensive Specialized Hospital. Gondar is known for attracting the largest number of tourists, is situated in Northwestern Ethiopia at a distance of $724 \mathrm{~km}$ from Addis Ababa (the capital) and 175km from the nearby city of Bahir Dar. It has a total population of 700044 with area $192.27 \mathrm{~km}^{2}$ according to the 2007 census. This city is the place of historical, religious, cultural treasures recognized by UNESCO, constituting churches and palaces. Gondar was serving as the capital city of the Ethiopian Empire during the medieval period

The University of Gondar Comprehensive Specialized Hospital is among the largest tertiary teaching hospital in Ethiopia. It was established in 1954, this is the oldest medical training institution in the country and located in the historical town of Gondar. This comprehensive specialized hospital is providing health care for an estimate of around 5 million people and it has been rendering health care services for more than six decades and currently. The previous study showed that 579 health professionals, 262 Nurses, 123 physicians, and the remains other professionals; around 17 wards that have 500 beds; the total number of patients admit in the hospital per month were 314 , and per annually 3,768 from surgical wards (28). Specifically, in my study setting, there are 67 nurses and 28 physicians 
that have been providing 815 physical trauma admitted patients at monthly and per annually was 9,780 in inpatient wards ( Surgical ward, Orthopedic ward, and Trauma ward).

The Felege-Hiwot comprehensive specialized hospital is found in the capital city of the Amhara Regional state which is located $553 \mathrm{~km}$ far from the capital city of Ethiopia, Addis Ababa. It was established in 1963 as a district hospital and changed into a referral hospital in 2002 and into a comprehensive specialized hospital in 2019. This gives clinical services to 5.5 million People. Specifically, in my study wards, there were 27 nurses and 12 physicians that have been providing 400 adult trauma patients per month and 4,800 per annually were getting the service at surgical and orthopedic wards.

\section{Sample size calculation and sampling technique}

The sample size was calculated by using a single population proportion formula involving using Epi-info version seven with a $95 \% \mathrm{Cl}$, a $5 \%$ margin of error, and the prevalence of depression of $50 \%$ due to lack of published work in Ethiopia. Having assumed a $10 \%$ of non-response rate, 422 participants were recruited randomly by using systematic sampling technique. The study participants were selected from the patients' charts/admission register by using a systematic random sampling technique from the two hospitals. The sample was proportionally taken from the independent hospitals, which were determined based on admitted to the wards in a month. Based on the current information at the inpatients, 1,215 traumatized patients are admitted monthly in these wards to fill the required sample size of 422 individuals. The total sample size in Felege-Hiwot was 139 and in Gondar University was 283 as a proportional formula; the sampling interval also was allocated proportionally to each study setting, which was determined by dividing the total study population during one month of data collection period. The first study subject was selected by lottery method. Therefore, participants were selected every two intervals starting from the first randomly selected participant.

\section{Data collection procedure and tools}

Data were collected using an interviewer-administered questionnaire, which contains several other explanatory variables include socio-demographic characteristics (age, sex, educational, marital status, occupation, and others), clinical factors (anxiety, medication, history of psychiatry illnesses, chronic medical illnesses, type of trauma, history of trauma), psychosocial factors (social support and Perceived life-threatening) and substance use factors (alcohol, tobacco, khat, Cannabis), which was collected by structured and semi-structured questionnaires, the following instruments were employed:

Anxiety was collected with a standard questionnaire (GAD-7 scale) that has a sensitivity with $89 \%$ and specificity with $82 \%(29)$; which was validated in Ethiopia and its Cronbach's alpha with 0.82 (30). Data on the depression were collected through interviews using a standard questionnaire, Patient Health Questionnaire (PHQ-9) which is a 9-item depression screening and diagnostic questionnaire for the depressive symptoms based on the Diagnostic Statistical Manual-IV criteria with sensitivity $86 \%$ and specificity $67 \%$ and it was developed by Bizu Belaye in 2011, it has Cronbach's alpha with 0.85 with Amharic version; patients scoring 10 or more were classified as having depression in Ethiopia. The score 
for each question varies from 0 to $3(0=$ not at all, $1=$ several days, $2=$ more than half of the day, $3=$ nearly every day), with a result range of $0-27$ (31).

Social support was assessed by using the Oslo 3-item social support scale and used several studies. It provides a brief measure of social support and functioning and is considered to be one of the best predictors of mental health. It covered different levels of social support by measuring the number of people the respondents feel close to, the interest and concern showed by others, and the ease of obtaining practical help from others. To OSS-3, total scores was calculated by adding up the raw scores for each item. The sum score scale ranges from 3 to 14 and has three broad categories: "Poor social support" 3-8, "Moderate support" 9-11, and "Strong support" 12-14 (32-34).

Substance use factors were conducted by using WHO's ASSIST which is developed by the World Health Organization and its Cronbach's alpha with 0.80 , sencitivity with $80 \%$, and specificity with $71 \%$.

Perceived threat to life was measured using Perceived Stress Scale(PSS) with its scores, which ranges from 0 to 40 with higher scores indicating higher perceived stress, low perceived stress scores ranging from $0-13$ on PSS, moderate perceived stress scores ranging from 14-26 on PSS and high perceived stress scores ranging from $27-40$ on PSS-10 items (35) and it was validated with Cronbach'salpha with 0.80 .

\section{Data processing and analysis}

The completed questionnaire was checked for completeness and then was coded, recoded, and entered into Epi-info version 7 statistical programs and then was exported to SPSS 20 for analysis. Binary logistic regression was used to identify factors associated with acute stress disorder which $p$-value was less than 0.2 levels. All variables significantly associated with binary logistic regression which was entered into the multivariable logistic regression. Finally, the variables that had an independent association with acute stress disorder were declared on $95 \% \mathrm{Cl} \mathrm{P-value}<0.05$.

\section{Results}

Socio-demographic characteristics

A total of $(n=422)$ physically traumatized patients have completed the study with a response rate of $100 \%$. The median age of participants was 36 (SD \pm 13 ) with age ranging from 18 to 72 years. Out of the study participants, $289(68.5 \%)$ were males, and more than half of $52.6 \%$ were singles. Of the participants about three-fourths $76.3 \%$ belong to Orthodox Christian followers and $84.1 \%$ of were Amhara by their ethnicity. More than two-fifths of (43.1\%) of participants were unable to read and write, half of respondents $(50.9 \%)$ were rural dwellers, and $32.8 \%$ of participants were farmers (Table 1 ). 
Table 1

Socio-demographic characteristics of the study participants at Gondar and Felege-Hiwot comprehensive specialized Hospitals, Northwest Ethiopia $(n=422)$.

\begin{tabular}{|c|c|c|c|}
\hline Variables & Categories & Frequency & Percent \\
\hline \multirow[t]{2}{*}{ Sex } & Male & 289 & 68.5 \\
\hline & Female & 133 & 31.5 \\
\hline \multirow[t]{6}{*}{ Age group } & $18-20$ years & 63 & 14.9 \\
\hline & $21-29$ years & 99 & 23.5 \\
\hline & 30-39years & 93 & 22.0 \\
\hline & $40-49$ years & 92 & 21.8 \\
\hline & $50-59$ years & 46 & 10.9 \\
\hline & $>59$ & 29 & 6.9 \\
\hline \multirow[t]{4}{*}{ Marital status } & Married & 118 & 28.0 \\
\hline & Single & 197 & 46.7 \\
\hline & Divorced & 96 & 22.7 \\
\hline & Separated/widowed & 11 & 2.6 \\
\hline \multirow[t]{3}{*}{ Religion } & Orthodox & 322 & 76.3 \\
\hline & Muslim & 69 & 16.4 \\
\hline & Protestant/Catholic & 31 & 7.3 \\
\hline \multirow[t]{3}{*}{ Ethnicity } & Amhara & 355 & 84.1 \\
\hline & Oromo & 47 & 11.2 \\
\hline & Other* & 20 & 4.7 \\
\hline \multirow[t]{6}{*}{ Education } & Unable to read and write & 182 & 43.1 \\
\hline & $1-8$ grade & 105 & 24.9 \\
\hline & $9-10$ grade & 41 & 9.7 \\
\hline & $11-12$ grade & 33 & 7.8 \\
\hline & Diploma & 25 & 5.9 \\
\hline & Degree and above & 26 & 8.5 \\
\hline Residence & Rural & 215 & 50.9 \\
\hline
\end{tabular}

Other*=Kemant, Agew and Gumz: Other**=Daily laborer, Driver 


\begin{tabular}{|llll|}
\hline Variables & Categories & Frequency & Percent \\
\hline \multirow{3}{*}{ Occupation } & Urban & 207 & 49.1 \\
& Employee & 63 & 14.9 \\
\cline { 2 - 4 } & Merchant & 99 & 23.5 \\
\cline { 2 - 4 } & Farmer & 138 & 32.7 \\
\cline { 2 - 4 } & Student & 49 & 11.6 \\
\cline { 2 - 4 } & Others ${ }^{\star *}$ & 53 & 12.6 \\
\hline Other ${ }^{*}=$ Kemant, & Agew and Gumz: Other**=Daily laborer, Driver \\
\hline
\end{tabular}

\section{Clinical, psychosocial, and substance characteristic of the study participants}

Regarding the clinical characteristic of study subjects; $33.2 \%(n=140)$ of participants experienced gunshot traumatic events and $20.4 \%(n=86)$ of respondents had anxiety. Of the participants, more than one-tenth $12.3 \%$ had taken psychiatric medication, $8.5 \%(n=36)$ of the participants had past traumatic history, 7.6\% $(n=32)$ had past psychiatry illness, 6.2\% $(n=26)$ had the chronic medical illness and $5.7 \%$ $(n=24)$ had a family history of psychiatry illnesses. Nearly one-third of the participants $(30.6 \%)$ had low perceived stress (based on the cut-off score less than or equal to 13 as measured by perceived stress scale-10). Over one-thirds $38.9 \%$ of study participants had poor social support. Regarding alcohol use, over two-fifth $43.1 \%$ were drinking once in their lifetime while alcohol is being currently consumed by $17.8 \%$ of them. A smaller proportion of the participants (9.1\%) were found to be current chewers of khat (also called chat in Ethiopia)(Table 2). 
Table 2

Clinical, psychosocial, and substance use characteristics of the study participants.

\begin{tabular}{|c|c|c|c|}
\hline Variables & Categories & Frequency & Percent \\
\hline \multirow[t]{2}{*}{ Past psychiatric history } & Yes & 32 & 7.6 \\
\hline & No & 390 & 92.4 \\
\hline \multirow[t]{2}{*}{ Family history of psychiatry } & Yes & 24 & 5.7 \\
\hline & No & 398 & 94.3 \\
\hline \multirow[t]{2}{*}{ History of psychiatric medication } & Yes & 52 & 12.3 \\
\hline & No & 370 & 87.7 \\
\hline \multirow[t]{5}{*}{ Type of trauma } & Car accident & 124 & 29.4 \\
\hline & Gunshot & 140 & 33.2 \\
\hline & Falling down & 64 & 15.2 \\
\hline & Burn & 51 & 12.1 \\
\hline & Physical fight/bit & 43 & 10.2 \\
\hline \multirow[t]{2}{*}{ Chronic medical illness } & Yes & 26 & 6.2 \\
\hline & No & 396 & 93.8 \\
\hline \multirow[t]{2}{*}{ History of trauma } & Yes & 36 & 8.5 \\
\hline & No & 386 & 91.5 \\
\hline \multirow[t]{2}{*}{ Anxiety } & Yes & 86 & 20.4 \\
\hline & No & 336 & 79.6 \\
\hline \multirow[t]{3}{*}{ Social support } & Poor support & 164 & 38.9 \\
\hline & Moderate support & 138 & 32.7 \\
\hline & Strong support & 120 & 28.4 \\
\hline \multirow[t]{3}{*}{ Perceived life threaten } & Low perceived stress & 250 & 59.2 \\
\hline & Moderate perceived stress & 129 & 30.6 \\
\hline & High perceived stress & 43 & 10.2 \\
\hline \multicolumn{4}{|l|}{ Ever use } \\
\hline \multirow[t]{2}{*}{ Alcohol } & Yes & 182 & 43.1 \\
\hline & No & 240 & 56.9 \\
\hline Khat & Yes & 46 & 10.9 \\
\hline
\end{tabular}




\begin{tabular}{|c|c|c|c|}
\hline Variables & Categories & Frequency & Percent \\
\hline & No & 376 & 89.1 \\
\hline \multicolumn{4}{|l|}{ Current use } \\
\hline \multirow[t]{5}{*}{ Alcohol } & Never & 251 & 59.7 \\
\hline & Once and twice & 48 & 11.4 \\
\hline & Weekly & 35 & 8.3 \\
\hline & Monthly & 12 & 2.8 \\
\hline & Daily & 75 & 17.8 \\
\hline \multirow[t]{5}{*}{ Khat } & Never & 384 & 91.0 \\
\hline & Once and twice & 5 & 1.2 \\
\hline & Weekly & 5 & 1.2 \\
\hline & Monthly & 2 & 0.5 \\
\hline & Daily & 26 & 6.2 \\
\hline
\end{tabular}

\section{Prevalence and the associated factors of depression}

In this study, the prevalence of depression among study participants was found to be $37.2 \%(95 \%, \mathrm{Cl}$ : $32.7 \%, 41.5 \%)$. Sex, marital status, types of trauma, past history of trauma, chronic medical illnesses, history of psychiatry medication, family history of psychiatric illness, anxiety, social support, and perceived threat in life were factors significantly associated with depression at a P-value below 0.2 in bivariate logistic regression. After controlling potential confounding factors in the multivariate analysis, findings showed that being single, having chronic medical illness, anxiety, poor and moderate social support, and moderate stress in life threaten events were factors significantly associated with depression P-value less than 0.05 .

After controlling potential confounding factors in the multivariate analysis, findings showed that being single were 2.36 times more likely to develop depression as compared with participants who were married $(\mathrm{AOR}=2.36,95 \%, \mathrm{Cl}: 1.31,4.21)$, and the odds of developing depression among participants history of chronic medical illness were about 3.79 times higher than those who had no chronic medical illness $(A O R=3.79,95 \%, \mathrm{Cl}: 1.19,12.08)$. In the present study, the respondents with anxiety symptoms were 3.81 times higher to develop depression compared to participants who had no anxiety symptoms (AOR $=3.81$, $95 \%, \mathrm{Cl}: 2.11,6.85)$. Poor and moderate social supports were 4.60 and 4.34 times more risky to have depression compared with their counterparts $(\mathrm{AOR}=4.59,95 \%, \mathrm{Cl}: 2.36,8.91)$ and $(\mathrm{AOR}=4.34,95 \%, \mathrm{Cl}$ : $2.23,8.45)$, respectively. The odds of developing those participants who reported to have experienced a moderate perceived threat to life were 2.66 times higher odds of developing depression compared to participants who did not have the perceived threat for life (AOR $=2.66,95 \%, \mathrm{Cl}: 1.58,4.47$ ) (Table 3). 
Table 3

Factors associated with depression among physical traumatized patients.

\begin{tabular}{|c|c|c|c|c|}
\hline \multirow[t]{2}{*}{ Variables } & \multicolumn{2}{|c|}{ Depression } & \multirow[t]{2}{*}{ COR $(95 \% \mathrm{Cl})$} & \multirow[t]{2}{*}{ AOR $(95 \%, \mathrm{Cl})$} \\
\hline & Yes & No & & \\
\hline \multicolumn{5}{|l|}{ Sex } \\
\hline Male & 93 & 196 & 1 & 1 \\
\hline Female & 64 & 69 & $1.60(1.28,2.98)$ & $1.52(0.89,2.60)$ \\
\hline \multicolumn{5}{|l|}{ Marital status } \\
\hline Married & 28 & 90 & 1 & 1 \\
\hline Single & 87 & 110 & $2.54(1.52,4.22)$ & $2.36(1.31,4.21)^{\star}$ \\
\hline Divorce & 38 & 58 & $2.10(1.17,3.80)$ & $1.76(0.87,3.57)$ \\
\hline Separated/widowed & 4 & 7 & $1.83(0.50,6.73)$ & $0.59(0.10,3.26)$ \\
\hline \multicolumn{5}{|l|}{ Types of trauma } \\
\hline Car accident & 54 & 70 & $1.78(0.84,3.73)$ & $1.50(0.61,3.62)$ \\
\hline Gunshot & 44 & 96 & $1.06(0.50,2.22)$ & $0.90(0.36,2.23)$ \\
\hline Falling down & 28 & 36 & $1.80(0.79,4.06)$ & $1.15(0.43,3.07)$ \\
\hline burn & 18 & 33 & $1.26(0.52,3.00)$ & $0.79(0.28,2.24)$ \\
\hline Physical fight/bit & 13 & 30 & 1 & 1 \\
\hline \multicolumn{5}{|l|}{ Psychiatry medication } \\
\hline Yes & 29 & 23 & $2.38(1.32,4.29)$ & $1.19(0.46,3.10)$ \\
\hline No & 128 & 242 & 1 & 1 \\
\hline \multicolumn{5}{|c|}{ Chronic medical illness } \\
\hline Yes & 19 & 7 & $5.08(2.08,12.37)$ & $3.80(1.19,12.08) \star$ \\
\hline No & 138 & 258 & 1 & 1 \\
\hline \multicolumn{5}{|c|}{ History of traumatic events } \\
\hline Yes & 21 & 15 & $2.57(1.29,5.16)$ & $0.86(0.30,2.39)$ \\
\hline No & 136 & 250 & 1 & 1 \\
\hline \multicolumn{5}{|c|}{ Family history of psychiatry } \\
\hline Yes & 12 & 12 & $1.74(0.76,3.80)$ & $1.29(0.47,3.51)$ \\
\hline
\end{tabular}




\begin{tabular}{|c|c|c|c|c|}
\hline \multirow[t]{2}{*}{ Variables } & \multicolumn{2}{|c|}{ Depression } & \multirow[t]{2}{*}{$\operatorname{COR}(95 \% \mathrm{Cl})$} & \multirow[t]{2}{*}{ AOR $(95 \%, \mathrm{Cl})$} \\
\hline & Yes & No & & \\
\hline No & 145 & 253 & 1 & 1 \\
\hline \multicolumn{5}{|l|}{ Anxiety } \\
\hline No & 97 & 239 & 1 & 1 \\
\hline Yes & 60 & 26 & $5.69(3.39,9.53)$ & $3.81(2.11,6.85)^{\star \star \star}$ \\
\hline \multicolumn{5}{|l|}{ Social support } \\
\hline Poor support & 77 & 87 & $4.70(2.63,8.39)$ & $4.59(2.36,8.91)^{\star \star \star}$ \\
\hline Moderate support & 61 & 77 & $4.21(2.32,7.62)$ & $4.34(2.23,8.45)^{\star \star \star}$ \\
\hline Strong support & 19 & 101 & 1 & 1 \\
\hline \multicolumn{5}{|c|}{ Perceived life threaten } \\
\hline Low stress & 68 & 182 & 1 & 1 \\
\hline Moderate stress & 73 & 56 & $3.49(2.23,5.44)$ & $2.66(1.58,4.47)^{\star}$ \\
\hline High stress & 16 & 27 & $1.59(0.80,3.12)$ & $0.81(0 . .35,1.87)$ \\
\hline
\end{tabular}

\section{Discussion}

In the present hospital-based institutional cross-sectional study, the interesting findings were obtained. Participants having a being single, history of chronic medical illness in the past, anxiety, poor and moderate social support, and exposure to moderate stress for threatening life events were significantly associated with depression of participants. In this section, the major findings of the present study are discussed in light of previous empirical evidence from the literature. Attempts were made to provide sufficient justifications on unique outcomes of this study in a way it can best explain the study prevailing cultural, political as well as the socio-economic context of Ethiopia at a current time.

\section{Discuss the prevalence of depression}

Depression is the most common and the main public health matter after an exposed physical trauma, and it was a serious problem for traumatized adult people who met the criteria for depression. This study showed that the prevalence of depression among study participants was found $37.2 \%$ (95\%, $\mathrm{Cl} ; 32.7 \%$, $41.5 \%$ ). The magnitude of this study is in line with other studies conducted at intensive care unit in UK $40 \%$. However, this current study was lower than the study done in Massachusetts General Hospital, Boston 45\%, in Canada 67\%, at hospital in India 68\% and orthopedic hospital in UK 50\% (36-39). The 
possible reason for the discrepancy might be differences in study design, instruments, the nature of the accident, and sample size used.

On the contrary, this finding of the current study is higher than those of other studies conducted in Vietnam veternals hospital $19 \%$, in Brazil $30.5 \%$, in Los Angeles 31\%, in the New work city $26 \%(20,40-$ 42). The variations seen in the above magnitude of depression reported in different countries compared to the prevalence of this disorder in the current study might be due to differences in methods and procedures of data collection followed, study setting, types of study design, application of measurement tools which was not properly adapted to suit the cultural context of some studies differences in the types of population and the prevailing socio-cultural and economic contrasts between Ethiopia and the other countries.

Among significantly associated factors with depression; the participants with chronic medical illness were about three times more likely to develop depression compared to those who had no the chronic medical illness. This may be due to chronic medical illness challenges useful coping style of survivors(43) and way of life changes after physical trauma that may possibly contribute to increase morbidity and immune inhibition while chronic stress has an important result on the immune structure which eventually apparent an illness by arising neuro-chemical that reduce the immune system(44).

The participants with currently being single were about two times more likely to have depression compared to those who were currently married. This finding is supported by a study conducted in $\mathrm{New}$ work city (40). This might be due to not having of intimate social support to share stressful feelings, having low self-esteem and poor coping styles which are frequent along with being single individuals exposing them to have depression this study was supported in Bahir Dar(45). Depressive occurs mainly often in people with no close intimate relationships and is more common in being single individuals than among married persons, but this variation can reflect the early onset and the resulting marital discord feature of the disorder(46).

Participants who had anxiety were three times odds to develop depression compared to respondents who had not anxiety. This may be due to anxiety may be worsen the projection of the illness and obviously increase the risk among patients who have depression. Individuals with anxiety also may have a high risk of current co-morbid depression(46).

The present study demonstrated that participants who have poor social support were more than four times more possibility to develop depression compared to the participants who have strong social support. This finding is consistent to established and consistent previous findings that indicated the inverse association between received social support and vulnerability to depression, such as findings reported in Denmark (47). Having poor social support after experienced traumatic events might lead to mental health problems while good social support may minimize the negative results of traumatic injury. Besides, individuals who received inadequate and poor social support may not likely develop effective coping mechanisms to the adverse effects of trauma, and hence such people are susceptible to depression. 
The odds of developing depression of the participants among those with moderate perceived stress to life events in the current study were found more than two times higher compared to the participants who had low perceived stress such an event. The present finding is supported by previous study conducted in San Diego in the United States (48). Such findings may be justified by the fact that negative beliefs about the consequences of an adverse event are threatening to one's life may the onset of depression, because of irrational thinking and distorted intact belief, as consistently reported by adherents of rational emotive behavior therapists regarding the etiology of a disorder (49).

Strength and limitation of the study

The fact that this study has come up with some vital findings of depression although this topic was not studied in Ethiopia and with the paucity of evidence about this disorder among people in Africa, it can be taken as the strength of the study. Besides, since the present study was based on a cross-sectional study making an inference of causal relationship between independent and outcome variable (depression) is not possible.

\section{Conclusion}

In this study revealed that depression among physical trauma patients was considerable too high (37.2\%). Being single, having moderate perceived stress, anxiety, chronic medical illness, and poor social support were factors significantly associated with depression. The ministry of health and other concerned health organizations may find the current finding useful for early detection, prevention, and intervention strategies to minimize the factor of depression in trauma survivors. Researchers should conduct a further study on depression and its multiple impact on physical, mental, occupational and social functioning of people exposed for varieties of traumatic events using a different approach, including other study variables and designs, such as prospective cohort and case control in this study area as well as different parts of the country for further exploration of the problem.

\section{Abbreviations}




\begin{tabular}{|ll|}
\hline AOR & Adjusted Odds Ratio \\
\hline ASD & Acute Stress Disorder \\
\hline CI & Confidence Interval \\
\hline DSM & Diagnostic and Statistical Manual for Mental Disorder \\
\hline EPI-Info & Epidemiological Information \\
\hline GAD-7 & Generalized Anxiety Disorder 7-item (GAD-7) scale \\
\hline OSS-3 & Oslo 3 Items Social Support Scale \\
\hline UOGCSH & University Of Gondar Comprehensive Specialized Hospital \\
\hline RTA & Road Traffic Accident \\
\hline SPSS & Statistical Package for Social Sciences \\
\hline UOG & University of Gondar \\
\hline WHO & World Health Organization \\
\hline
\end{tabular}

\section{Declarations}

\section{Ethical consideration}

Ethical Approval and ethical clearance were obtained from the Institutional Review Board (IRB) and ethical clearance committee of the University of Gondar. A formal permission letter was obtained and it was taken to the University of Gondar and Felege-Hiwot comprehensive specialized hospital for administrative approval before the data collection. Participants were informed about the aim of study and advantage of study; confidentiality, there is no risk of being participants and they have full rights to stop in the middle of the interview. The risk and the benefit of the study were clearly explained to the participants through the information sheet before obtaining their consent. Written formal consent was obtained from each study participant. For those patient participants who cannot read and write, they were assisted to provide their consent through their fingerprint. For the respondents were found with positive for depression during the data collection period, linked to psychiatric clinic were done in order to get further evaluation on their condition.

\section{Consent for publication}

Not applicable

\section{Availability of data and materials}

The dataset during and/or analyzed during the current study available from the corresponding author on reasonable requests 


\section{Competing interests}

None declared

\section{Funding}

The authors have not declared a specific grant for this research from any funding agency in the public, commercial or not-for-profit sectors. The funder has no role in collection, analysis and interpretation of data and in writing the manuscript

\section{Authors' contributions}

Asnakew, W conceived the study and was involved in the study design, reviewed the article, analysis, report writing, and drafted the manuscript. GT, and BG were involved in the study design, analysis and drafted the manuscript. All authors read and approved the final manuscript.

\section{Acknowledgments}

First of all, we would like to thank the University of Gondar, College of Medicine and Health Sciences, Department of Psychiatry for organizing this research program. Secondly, our heartfelt thanks also extend to the University of Gondar, comprehensive specialized hospital staffs for their assistance to get the data of patients to determine sample size and their help during a data collection time. Finally, we would like to thank our study participants for their cooperation in providing the information.

\section{References}

1. Karakaya I, Çolak B. Çocuk ve Ergenlerde Travma Sonrası Stres Bozukluğu ve Adli Tıbbi Değerlendirme. Adli Tıp Bülteni. 2007;12(2):82-7.

2. Association AP. Diagnostic and statistical manual of mental disorders (DSM-5®): American Psychiatric Pub; 2013.

3. Ari AB, Peri T, Margalit D, Galili-Weisstub E, Udassin R, Benarroch F. Surgical procedures and pediatric medical traumatic stress (PMTS) syndrome: Assessment and future directions. Journal of pediatric surgery. 2018;53(8):1526-31.

4. Organization WH. Injuries and violence: the facts. 2010.

5. Organization WH. World Report on Violence and Health. 2002.

6. Bonnie RJ, Fulco CE, Liverman CT. Reducing the burden of injury: advancing prevention and treatment: National Academies Press; 1999.

7. Lipsky S, Caetano R, Field CA, Bazargan S. Violence-related injury and intimate partner violence in an urban emergency department. Journal of Trauma and Acute Care Surgery. 2004;57(2):352-9.

8. Ophuis RH, Olij BF, Polinder S, Haagsma JA. Prevalence of post-traumatic stress disorder, acute stress disorder and depression following violence related injury treated at the emergency department: 
a systematic review. BMC psychiatry. 2018;18(1):311.

9. Peden M, Scurfield R, Sleet D, Mohan D, Hyder AA, Jarawan E, et al. World report on road traffic injury prevention. World Health Organization Geneva; 2004.

10. Vissoci JRN, Shogilev DJ, Krebs E, Andrade Ld, Vieira IF, Toomey N, et al. Road traffic injury in subSaharan African countries: A systematic review and summary of observational studies. Traffic injury prevention. 2017;18(7):767-73.

11. Tayeb SE, Abdalla S, Mørkve O, Heuch I, Van den Bergh G. Injuries in Khartoum state, the Sudan: a household survey of incidence and risk factors. International journal of injury control and safety promotion. 2014;21(2):144-53.

12. Moshiro C, Heuch I, Åstrøm AN, Setel P, Hemed Y, Kvåle G. Injury morbidity in an urban and a rural area in Tanzania: an epidemiological survey. BMC public health. 2005;5(1):11.

13. Tsegaye F, Abdella K, Ahmed E, Tadesse T, Bartolomeos K. Pattern of fatal injuries in Addis Ababa, Ethiopia: a one-year audit. East and Central African Journal of Surgery. 2010;15(2):10-7.

14. Bashah DT, Dachew BA, Tiruneh BT. Prevalence of injury and associated factors among patients visiting the Emergency Departments of Amhara Regional State Referral Hospitals, Ethiopia: a crosssectional study. Bmc emergency medicine. 2015;15(1):20.

15. Rapsang AG, Shyam DC. Scoring systems of severity in patients with multiple trauma. Cirugía Española (English Edition). 2015;93(4):213-21.

16. Yousuf A, Ramli Musa MLM, Isa SRMA. Anxiety and Depression Among Women Living with HIV: Prevalence and Correlations. Clinical Practice and Epidemiology in Mental Health: CP \& EMH. 2020;16:59.

17. Bitew T. Prevalence and risk factors of depression in Ethiopia: a review. Ethiopian journal of health sciences. 2014;24(2):161-9.

18. O’Donnell ML, Creamer M, Pattison P. Posttraumatic stress disorder and depression following trauma: understanding comorbidity. American Journal of Psychiatry. 2004;161(8):1390-6.

19. Zatzick DF, Jurkovich GJ, Fan M-Y, Grossman D, Russo J, Katon W, et al. Association between posttraumatic stress and depressive symptoms and functional outcomes in adolescents followed up longitudinally after injury hospitalization. Archives of Pediatrics \& Adolescent Medicine. 2008;162(7):642-8.

20. Shalev AY, Freedman S, Peri T, Brandes D, Sahar T, Orr SP, et al. Prospective study of posttraumatic stress disorder and depression following trauma. American Journal of psychiatry. 1998;155(5):630-7.

21. Holbrook TL, Hoyt DB, Coimbra R, Potenza B, Sise M, Anderson JP. Long-term posttraumatic stress disorder persists after major trauma in adolescents: new data on risk factors and functional outcome. Journal of Trauma and Acute Care Surgery. 2005;58(4):764-71.

22. Santiago PN, Ursano RJ, Gray CL, Pynoos RS, Spiegel D, Lewis-Fernandez R, et al. A systematic review of PTSD prevalence and trajectories in DSM-5 defined trauma exposed populations: intentional and non-intentional traumatic events. PloS one. 2013;8(4):e59236. 
23. BRYANT RA, HARVEY AG. The influence of traumatic brain injury on acute stress disorder and posttraumatic stress disorder following motor vehicle accidents. Brain Injury. 1999;13(1):15-22.

24. Frommberger UH, Stieglitz R-D, Nyberg E, Schlickewei W, Kuner E, Berger M. Prediction of posttraumatic stress disorder by immediate reactions to trauma: a prospective study in road traffic accident victims. European archives of psychiatry and clinical neuroscience. 1998;248(6):316-21.

25. Tsay SL, Halstead MT, McCrone S. Predictors of coping efficacy, negative moods and post-traumatic stress syndrome following major trauma. International journal of nursing practice. 2001;7(2):74-83.

26. Barton KA, Blanchard EB, Hickling EJ. Antecedents and consequences of acute stress disorder among motor vehicle accident victims. Behaviour Research and Therapy. 1996;34(10):805-13.

27. Bryant RA, Harvey AG. Acute stress disorder: A handbook of theory, assessment, and treatment: American Psychological Association; 2000.

28. Alemu WG, Malefiya YD. Prevalence and associated factors of common mental disorders among patients admitted in Gondar university hospital medical and surgical wards, northwest Ethiopia.

29. Spitzer RL, Kroenke K, Williams JB, Löwe B. A brief measure for assessing generalized anxiety disorder: the GAD-7. Archives of internal medicine. 2006;166(10):1092-7.

30. Belayihun B, Mavhandu-Mudzusi AH. Effects of surgical repair of obstetric fistula on severity of depression and anxiety in Ethiopia. BMC psychiatry. 2019;19(1):58.

31. Gelaye B, Williams MA, Lemma S, Deyessa N, Bahretibeb Y, Shibre T, et al. Validity of the patient health questionnaire-9 for depression screening and diagnosis in East Africa. Psychiatry research. 2013;210(2):653-61.

32. Abiola T, Udofia O, Zakari M. Psychometric properties of the 3-item oslo social support scale among clinical students of Bayero University Kano, Nigeria. Malaysian Journal of Psychiatry. 2013;22(2):3241.

33. Girma E. The prevalence of Psychological Distress and associated factors among Caregivers of Schizophrenia Outpatients: The Case of Amanuel Mental Specialized Hospital: Addis Ababa University; 2015.

34. Getnet B, Medhin G, Alem A. Symptoms of post-traumatic stress disorder and depression among Eritrean refugees in Ethiopia: identifying direct, meditating and moderating predictors from path analysis. BMJ open. 2019;9(1):e021142.

35. Cohen S, Kamarck T, Mermelstein R. Perceived stress scale. Measuring stress: A guide for health and social scientists. 1994;10:1-2.

36. Tomar S, Sharma A, Jain A, Sinha VD, Gupta ID. Study of fatigue and associated factors in traumatic brain injury and its correlation with insomnia and depression. Asian journal of neurosurgery. 2018;13(4):1061.

37. Degen RM, MacDermid JC, Grewal R, Drosdowech DS, Faber KJ, Athwal GS. Prevalence of symptoms of depression, anxiety, and posttraumatic stress disorder in workers with upper extremity complaints. journal of orthopaedic \& sports physical therapy. 2016;46(7):590-5. 
38. Nickinson RS, Board TN, Kay PR. Post-operative anxiety and depression levels in orthopaedic surgery: a study of 56 patients undergoing hip or knee arthroplasty. Journal of evaluation in clinical practice. 2009;15(2):307-10.

39. Crichlow RJ, Andres PL, Morrison SM, Haley SM, Vrahas MS. Depression in orthopaedic trauma patients: prevalence and severity. JBJS. 2006;88(9):1927-33.

40. Biggs QM, Fullerton CS, Reeves JJ, Grieger TA, Reissman D, Ursano RJ. Acute stress disorder, depression, and tobacco use in disaster workers following 9/11. American Journal of Orthopsychiatry. 2010;80(4):586.

41. Shih RA, Schell TL, Hambarsoomian K, Marshall GN, Belzberg H. Prevalence of PTSD and major depression following trauma-center hospitalization. The Journal of trauma. 2010;69(6):1560.

42. de Moraes VY, Jorge MR, Faloppa F, Belloti JC. Anxiety and depression in Brazilian orthopaedics inpatients: a cross sectional study with a clinical sample comparison. Journal of clinical psychology in medical settings. 2010;17(1):31-7.

43. Falcone T, Dickstein L, Sieke EH, Franco KN. You are here: Home/Cleveland Clinic Coping with Chronic Medical Illness Coping with Chronic Medical IIIness.

44. Salleh MR. Life event, stress and illness. The Malaysian journal of medical sciences: MJMS. 2008;15(4):9.

45. Ergetie T, Yohanes Z, Asrat B, Demeke W, Abate A, Tareke M. Perceived stigma among nonprofessional caregivers of people with severe mental illness, Bahir Dar, northwest Ethiopia. Annals of general psychiatry. 2018;17(1):42.

46. Kaplan BJ. Kaplan and sadock's synopsis of psychiatry. Behavioral sciences/clinical psychiatry. Tijdschrift voor Psychiatrie. 2016;58(1):78-9.

47. Cook JD, Bickman L. Social support and psychological symptomatology following a natural disaster. Journal of Traumatic Stress. 1990;3(4):541-56.

48. Holbrook TL, Hoyt DB, Coimbra R, Potenza B, Sise M, Anderson JP. High rates of acute stress disorder impact quality-of-life outcomes in injured adolescents: mechanism and gender predict acute stress disorder risk. Journal of Trauma and Acute Care Surgery. 2005;59(5):1126-30.

49. Ellis A, Dryden W. The practice of rational emotive behavior therapy: Springer publishing company; 2007. 